\title{
Pensar en formas sonoro-simbólicas
}

\author{
Desarrollo de un concepto para \\ el estudio semiológico del timbre
}

\author{
Jorge Sad Levi
}

[Universidad de Tres de Febrero]

Resumen En el presente artículo trataremos el problema de la significación de los fenómenos tímbricos en el marco de la semiología de Molino y Nattiez. Distinguimos el mero sonido en tanto vibración de las formas sonoro-simbólicas. Éstas últimas son el resultado de la acción intencional y exclusiva de un acto de producción/escucha y puede ser estudiada en su triple dimensión, en tanto hecho material, en tanto fenómeno perceptual y en tanto fenómeno imaginario. Las formas sonoro-simbólicas portan la signatura de cada operación de producción realizada por compositores, programadores de software, luthiers, diseñadores de sonido, productores discográficos y músicos.
Summary In this article we approach the signification of timbral phenomena within the frame of Molino and Nattiez's semiotic model. We distinguish sound as vibration from symbolic sound forms. The latter are the result of human being's intentional and exclusive act of sound production or reception and can be studied in it's triple dimension, as a material fact, as a perceived event in time and as an imaginary phenomena. Symbolic sound forms carry the signature of every sound production operation made by composers, luthiers, sound designers, phonographic producers and musicians. 


\section{INTRODUCCIÓN}

En este artículo nos proponemos investigar el problema del timbre a partir de la utilización crítica de la metodología semiológica tripartita concebida por Jean Molino y Jean-Jacques Nattiez. Sea que consideremos al timbre un concepto comodín (fourretout) como coinciden en describirlo personalidades con tan diferentes perspectivas teóricas como las de Michel Chion (Chion, 1986: 7) o René Caussé (Caussé, I99I: 216), o bien, lo consideremos como Nattiez un elemento musical secundario, incapaz de producir eventos implicativos para los oyentes competentes en el estilo de la música clásica y romántica (Nattiez, 2005), el problema del reconocimiento de las significaciones inmanentes de la materia sonora no deja de existir negándolo. Para Philipp Tagg, «El timbre es probablemente el parámetro de expresión musical más frecuentemente señalado por los estudiosos de la música popular, así como el punto ciego más serio de la teoría de la música convencional» (Tagg, 2015: II). La enorme cantidad de definiciones contradictorias o complementarias del concepto que es posible reconocer en un texto ya clásico como Le timbre: métaphore pour la composition (Barrière, 199I) demuestran que, como lo sostiene Claude Cadoz, «la cuestión del timbre no se reduce a su definición: el debate que suscita es un debate sobre el total de la música misma» (Cadoz, I99i: I7).

\section{Metodología}

De acuerdo a la definición dada por Jean Molino, quien sostiene que todo producto del hacer humano es una forma simbólica (Molino, 1975), resulta posible inferir que, tanto los sonidos producidos ${ }^{1}$ o escuchados ${ }^{2}$ intencionalmente, como los instrumentos y sistemas utilizados para realizarlos son parte de este grupo y, por lo tanto, ameritan la posibilidad de una interrogación semiológica que permita dar cuenta de las significaciones que éstos suscitan en tanto

\footnotetext{
1 Es importante subrayar la distinción entre emitir y producir un sonido: todos los sonidos emitidos por los seres humanos no son consecuencias de un "hacer", la mayoría de los sonidos que emitimos cotidianamente son consecuencias no intencionales de otras acciones como caminar, respirar, tipear, toser, etc.

2 El acto de escucha es un acto intencional. Todos los sonidos, mismo los silencios, reconocidos en un acto de escucha, pueden ser considerados formas simbólicas, mismo si no fueron producidos intencionalmente. Es posible pensar entonces que el acto de escucha es un "hacer", cuyo producto es la forma sonora. La transformación de un fenómeno audible en forma sonora es, sin duda, la consecuencia de una poiesis.
} 
objetos concebidos e imaginados, en tanto objetos materiales y en tanto objetos percibidos. Como sostiene André Schaeffner,

mudos, los instrumentos presentan en efecto una doble importancia. Son en principio signos: su materia, su forma exterior, el hecho que ellos guardan los sonidos, o podrían guardarlos (instrumentos votivos), están ligados a un conjunto de creencias, de hábitos y de necesidades humanas, que ellos traducen elocuentemente. Ellos se ubican en el entrecruzamiento múltiple de técnicas, artes y ritos. (Schaeffner, I968: 298) ${ }^{3}$

Utilizaremos la expresión «formas sonoro-simbólicas» o simplemente formas sonoras para evocar la noción de forma simbólica que propone Molino y lo utilizaremos tanto para aludir a sonidos que efectivamente suenan en un momento dado como para aquellos que resultan de la representación, la imaginación y la memoria ${ }^{4}$. Las formas sonoras existen como imagen e idea, especialmente para aquellos que las producen, antes que la música u otra forma simbólica que las utilice como material llegue a su concreción acústica. Denis Smalley en su artículo Spectromorphology: explaining sound-shapes utiliza el equivalente en inglés de la expresión "formas sonoras», pero solo alude a las formas sonoras de la música electroacústica y su perspectiva, estésico inductiva, en línea con el pensamiento de Pierre Schaeffer, intenta poner entre paréntesis la poiética de dichas formas sonoras: "In spectromorphological thinking we must try to ignore the electroacoustic and computer technology used in the music's making» (Smalley, r997).

En relación al recorte del objeto de nuestra investigación, de la misma manera que la semiología tripartita de Molino-Nattiez limita su objeto a la producción humana y excluye los signos naturales, limitaremos nuestro objeto de estudio a los sonidos producidos, representados, reproducidos o escuchados intencionalmente por seres humanos, lo que equivale a decir que las vibraciones fonógenas, no portadoras de una intención poiética o estésica humana estarán excluidas de nuestro cuadro de trabajo. Por el contrario, un sonido cualquiera escuchado atentamente, imaginado o recordado, puede ser considerado en todo derecho una forma sonora. Como sostiene Cadoz, «un fenó-

3 Todas las traducciones son del autor.

4 Cuando me refiero al "sonido de la guitarra de George Harrison en el solo de Something", si lo conozco, no me refiero al sonido en tanto fenómeno acústico sino a la imagen que luego de habituarme al mismo puedo representarme mentalmente sin necesidad de escucharlo físicamente. 
meno sonoro que no implique ninguna intervención humana no puede portar significación humana, un acto mínimo se requiere, aunque éste sea para designar a la escucha este fenómeno» (Cadoz, I99I: 34). Desde esta perspectiva, tanto las formas sonoras representadas, producidas, imaginadas y percibidas, como todo instrumento musical, elemento material, soporte, espacio o técnica de escucha interviniendo en su producción, serán también considerados formas sonoro-simbólicas.

La pregunta que nos formulamos podría ser expresada del siguiente modo: ¿Es posible pensar el «timbre» en tanto conjunto (virtualmente infinito) de reenvíos suscitados por las formas sonoras en quienes las estudian, las fabrican/producen o imaginan y en quienes las perciben? Consideramos que el abordaje del fenómeno del timbre no es directamente accesible sino por la mediación de un cuadro abarcativo que pueda dar cuenta del funcionamiento semiológico general del dominio de las formas sonoras. Se tratará aquí de incorporar como objeto de estudio la perspectiva de aquellos para quienes el sonido constituye el objeto de la poiesis, ya sea de manera directa como en la ejecución de un instrumento o la post producción de un disco, o de manera indirecta como en la composición escrita, la luthería o el diseño de una sala de concierto. Como lo afirma Kintzler,

\begin{abstract}
Crear sonidos [...] es ponerse en estado de proceder a esta operación de promoción y producir máquinas físicas e intelectuales de procesamiento que «escupen» a la salida sonido musical [...] estas máquinas son llamadas instrumentos de música pero conviene dar a esta nominación un sentido amplio. Un instrumento puede ser una máquina intelectual mínima por ejemplo una posición o una decisión de escucha. (Kintzler, 2003: 6)
\end{abstract}

\title{
¿SEMiología de LA MÚSiCA O SEMiología
}

DE LAS FORMAS SONORAS?

Una de las principales críticas que recibe la obra de Jean-Jacques Nattiez por la noción de nivel neutro está relacionada con el supuesto erróneo de no tener en cuenta el sonido como materia de la música, error conceptual en el que nosotros mismos hemos incurrido en artículos anteriores (Sad, 20I2). La posición de Nattiez es enormemente compleja y matizada, si bien es innegable que para el fundador de la corriente semiológica a la que pretendemos adscribir el fenó- 
meno sonoro se ubica en el nivel estésico, sea tanto a nivel de la interpretación como de la percepción, éste asume claramente que el producto de la interpretación es una forma simbólica y por lo tanto, consecuencia de una poiesis y escribe: «[...] cualquier configuración sonora, porque es una forma simbólica, puede ser el objeto de una exégesis y de un juicio» (Nattiez, 1998: 32). El autor dedicó un libro junto a Philippe Mion a la obra electroacústica De natura sonorum (1975) de Bernard Parmegiani, y se ha ocupado tanto del problema de la interpretación de la música antigua en "Autenticidad Fidelidad y Juicio Crítico» (Nattiez, 1998), como de la semántica musical en "Ethnologie et significations musicales» (Nattiez, 2004). Por otra parte, Nattiez siempre ha sostenido que su proyecto constituye una semiología, abriendo la posibilidad de la existencia de otras semiologías situadas en otros niveles de pertinencia y con otros objetos.

En cuanto a Jean Molino, una lectura atenta de Fait musical et sémiologie de la musique (Molino, 1975) muestra a las claras que el autor tiene en cuenta como componentes del hecho musical todos estos niveles no específicamente textuales, desde las teorías y los sistemas musicales, pasando por instrumentos, músicos, soportes, espacios de concierto, gestos, sonidos.

El problema de la semiología de la música de Nattiez no consistiría entonces en la introducción de la noción de nivel neutro, sino en la reducción de la multiplicidad de niveles materiales implicados en el hecho musi$\mathrm{cal}$ a las solas configuraciones inmanentes del texto.

\section{No UNO, SINO VARIOS NIVELES NEUTROS}

Construir un instrumento, interpretar, tocar, componer, imaginar sistemas de afinación, diseñar un programa informático de síntesis o procesamiento de sonido, grabar, producir un disco, diseñar el sonido de una película o una instalación, escuchar atentamente un paisaje sonoro, son actividades destinadas a producir directa o indirectamente formas sonoro simbólicas a través de una interfaz especifíca (escritura musical, medios electroacústicos, programas informáticos, micrófonos-parlantes, instrumentos de música, audición). Cada una de estas interfaces de producción de las formas sonoras puede ser considerada consecuencia de una poiética y por lo tanto, las formas sonoras resultantes tendrán tantos niveles inmanentes como etapas diferentes estén implicadas en su producción. El siguiente cuadro permitiría visualizar esta pluralidad de niveles o estratos que integran la poiesis de las formas sonoras. Cada uno de 
ellos constituye en sí un objeto semiótico diferente, susceptible de ser entendido como forma simbólica tripartita.

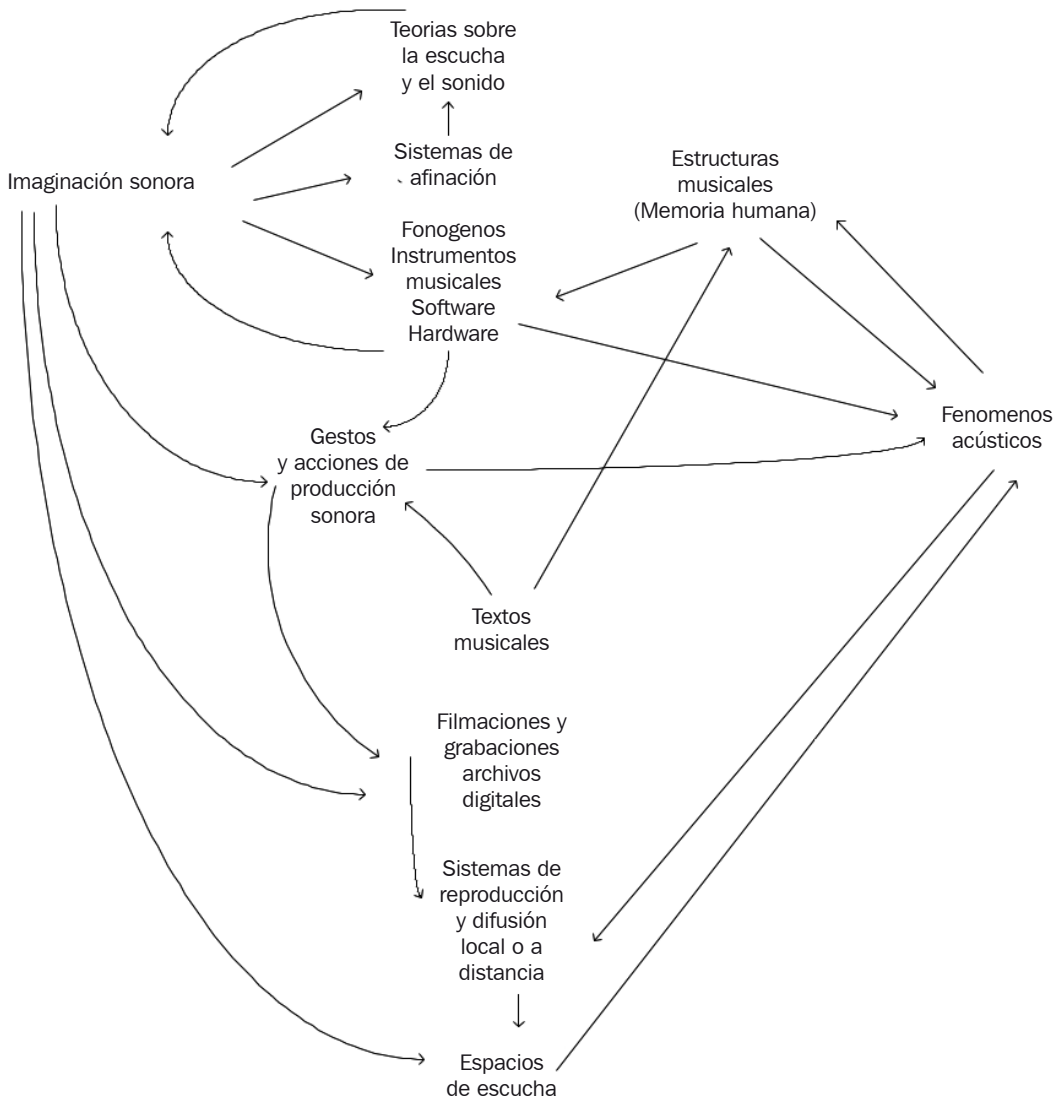

Figura $1 \sim$ Pluralidad de niveles o estratos que integran la poiesis de las formas sonoras.

Nótese que cada uno de estos niveles implica una poiesis que puede ser colectiva y anónima (como en el caso de las grandes creaciones de una cultura, como los sistemas de afinación o los instrumentos) o individuales (como en el caso de las obras de los compositores occidentales o la ejecución instrumental. Nótese también que cada uno de estos niveles puede ser tomado analíticamente de manera aislada o combinado con los restantes. En una simple 
grabación de una obra clásica para guitarra difundida en radio, encontramos en el análisis de la huella espectral la superposición de la poiética del compositor, del guitarrista, del ingeniero de sonido, del luthier, de equipamiento de grabación, de la ingeniería del soporte que permite conservarlo y reproducirlo y finalmente, el sistema de difusión que permitirá llegar a distancia. ¿Existirá algún día un algoritmo capaz de modelar la intervención de cada uno de estos factores en el resultado total?

Tomemos algunos ejemplos de creaciones relativamente contemporáneas que ya son clásicos:

$\sim$ En las obras de Karlheinz Stockhausen, Gruppen (1955-1957) y Zeitmasse (1955-1956): el objeto creado concierne no solo el texto musical, sino también al instrumento (en el caso de las tres orquestas en el espacio) y la teoría musical que lo sustenta (enunciada en "How time passes" -1959). En el caso de Elektronische Studie II (1954) ${ }^{5}$, la obra concierne los osciladores y el conjunto de equipamiento de estudio utilizado, al sistema de afinación, el texto instruccional escrito, finalmente a las vibraciones fonógenas codificadas sobre soporte y al objeto sonoro percibido. $\sim$ En el caso de Sgt.Peppers (1967) de The Beatles, el objeto creado no está constituido solamente por las estructuras melódico rítmicas de las canciones que permiten reconocerlas, sino por cada uno de los detalles espectromorfológicos de los objetos sonoros que las componen, su distribución en el espacio estereofónico, la distribución en el tiempo de dichas canciones en el soporte, la disponibilidad técnica (cuatro tracks) del estudio de Abbey Road ${ }^{6}$. El objeto así producido también delimita un espacio de escucha privado e individual que habitualmente es el living de los hogares, la escucha en automóviles o a través de auriculares, y no en un espacio público.

$\sim$ En el caso de De Natura Sonorum (1975) de Bernard Parmegiani es posible reconocer no sólo la poiética de la producción de las formas sonoras a nivel de los objetos musicales cuya referencia teórica sea probablemente el Tratado de los objetos musicales (1966) de Pierre Schaeffer, sino también de la forma global de la suite acusmática, pensada en relación al soporte, con su secuencia específica de tracks y de «lados», de

5 Parece ser un mito urbano, pero no por eso menos interesante como material de pensamiento, que Stockhausen dijo sobre la versión digital realizada en EMS, que no contenía ruido de cinta, que sonaba "como carillones".

6 En este punto, referimos al seminal artículo de Eliot Bates "What studios do" (2012). 
manera similar al ejemplo citado anteriormente de The Beatles, y otro rasgo en común con el ejemplo anterior, el equipamiento de estudio y el estudio mismo.

Cada uno de esos niveles poiéticos establece un recorte, caracterizado por el conjunto de posibilidades y restricciones operatorias que implica y determinan las subsecuentes acciones sobre la materia sonora. Las formas sonoras son, pues, consecuencia de una multiplicidad de gestos constructivos o expresivos, que imprimen en la materia las huellas de quién, quiénes, qué y cómo fueron producidas y, por lo tanto, permiten a ciertos oyentes en ciertas condiciones, inferir/reconstruir algunas de las intenciones y/o representaciones mentales de sus productores al tiempo que en algunos suscitan juicios de gusto, de valor y de atribución.

\section{Música / NO Música / RUIDo / SILENCIO}

Las músicas, el lenguaje poético, las producciones sonoras de pacientes en musicoterapia, el sonido en el cine, las señales sonoras en la vida cotidiana, el sonido de los videojuegos, los sonidos grabados y reproducidos, los sonidos escuchados atentamente, son todos formas sonoras simbólicas. Ellas pueden reenviar para distintos oyentes, escuchas y situaciones de escucha a causas puntuales o a grupos, estelas o nubes de interpretantes. Sonido, ruido, lenguaje poético, música y mismo la noción de silencio ${ }^{7}$ son algunos de los interpretantes que son asociados a menudo a las formas sonoras por sus usuarios: ellos no definen necesariamente una substancia o un objeto sino el reenvío a la experiencia vivida. Escucho un ruido que me gusta, lo bautizo música, como cuando los amantes del automovilismo hablan de la «música de motores» o cuando quienes desconocen un idioma a veces reconocen «la musicalidad» del mismo con más frecuencia que quienes lo hablan como lengua materna. El ex presidente argentino Juan Domingo Perón, en su último discurso público, dice a la multitud que colma la Plaza de Mayo, refiriéndose al estruendo de cánticos de las masas que lo acompañan «llevo en mis oídos la más maravillosa música [...] que es la palabra del pueblo argentino", coincidiendo en la descripción con ciertas alusio-

7 De hecho, si es imposible producir el silencio absoluto, es posible producirlo en tanto que símbolo por contigüidad a otras formas sonoras, en tanto espera atenta. Es posible pensar que el silencio es una forma sonora vacía. 
nes hechas por Iannis Xennakis hacia la misma época en relación a su inspiración en los sonidos producidos por las multitudes manifestándose en Grecia, para sus obras basadas en masas de sonidos distribuidos estocásticamente. Por el contrario, alguien escucha algo llamado música por otros pero del cual él mismo no gusta o no tiene la intención de escuchar: puede reducirlo a nivel de la señal (¿qué ese ruido que hacen los vecinos?) o establecer una analogía con un fenómeno sonoro no intencionalmente humano ("parece que el cantante ladra»). Para François Bernard Mâche,

puede ser que las terminologías usuales delimitando campos semánticos distintos (lenguaje, señales, obras musicales, ceremonias) no coincidan con los esquemas que se sitúan a nivel del psiquismo donde estas fronteras no están todavía trazadas. La ausencia de un término particular para significar «música» en esas sociedades [....] bastaría para mostrar que la instauración de una definición previa, con sus controversias inevitables, sería más una desventaja que una herramienta que garantice un procedimiento científico. (Mâche, 2000: 200)

Marie-Pierre Lassus, refiriéndose a la escritura de Bachelard, va a sostener que «la música comenzaba para él ya en la lengua, en los silencios y los timbres indispensables para que los humanos se comuniquen entre ellos» $y$ luego agregará que «en su escritura, - Bachelard - dispone cuidadosamente los puntos de suspensión, de exclamación, de interrogación, que dejaran resonar en el lector esta música de las palabras, tejida entre sonidos y silencios como lo haría un gong» (Lassus, 2010: I6). Para Jean Molino, «esa frontera incierta y móvil entre el lenguaje y la música pone en evidencia la imposibilidad de definir una música universal por su material: el fenómeno sonoro, pues forzaría entonces a hacer entrar en ella al lenguaje». (Molino, I975: 2). También el autor cita en el mismo texto a G. Calame-Griaule de quien dice que «ha mostrado de qué manera, entre los Dogon, la diferencia entre el canto y la palabra ordinaria no es una diferencia de naturaleza, sino, podríamos decir, de grado» (Molino, 1975). Michel Guiomar, en el mismo sentido sostiene: «Sonido musical, sonido literario y materia sonora son tres ramas divididas de un mismo lenguaje primitivo» (Guiomar, 1970: 30). Pierre Schaeffer aporta una definición mucho más tajante: «sonoro es lo que percibo. Musical ya es un juicio de valor». (Schaeffer, 1968: 28I) 
Para Cheyronnaud la asignación de estos interpretantes responde a una interrelación sistémica:

Confeccionamos cotidianamente entidades englobantes que llamamos familiarmente "música», «ruido», «silencio», afectando cada una a una vocación categorial al servicio de descripciones generalmente abiertas más o menos implícitamente a evaluación; es por otra parte una condición de su trabajo en conjunto permitir clasificar las ocurrencias acústicas, complejos sonoros organizados, tanto sobre las propiedades de una textura sonora que sobre los méritos «música», «silencio», «ruido» o las faltas que otorgamos afectiva y evaluativamente a lo que escuchamos. Las tres entidades están hechas en base al sonido, funcionan en red [...] querer asignar a lo que percibimos auditivamente como perteneciente a la "música», al "ruido» es seleccionar una de esas categorías y preferirla a las dos otras del mismo dominio (el del sonido), así como saber que servirse de una entre ellas es saber servirse de manera significante y apropiada de la referencia que configura su entresignificación. (Cheyronnaud, 20I2: 2OI)

En nuestra perspectiva, es justamente esta movilidad, esta frontera borrosa entre música y lenguaje y otras producciones sonoras lo que hace necesario considerar las formas sonoras simbólicas en tanto dominio semiológico singular, más allá de los estudios estructurales específicos sobre el lenguaje y sobre la música. Dado que «música» es un interpretante que ciertos «utilizadores» adhieren a determinadas formas sonoras, que puede incluir desde la producción de "Pocho La pantera» hasta la obra de Stockhausen, desde el noise al Chamamé, pasando por el paisaje sonoro, resulta necesario en términos de una investigación semiológica construir neologismos que permitan desarrollar conceptos totalmente nuevos en relación al problema investigado. Proponemos reservar la palabra música a la experiencia de comunicación efectiva (minoritaria, según Nattiez) en las que el polo estésico converge fuertemente con el polo poiético y propondremos la expresión formas sonoras para referirnos de manera general a todo fenómeno de producción sonora intencional reconocido también como intencional del lado estésico.

En el gráfico representamos entonces con color verde el total sonoro, objeto de estudio de la acústica; en rojo el grupo de los sonidos creados o escuchados intencionalmente por los seres humanos, objeto de estudio 
de la semiología de las formas sonoras; en azul la música, objeto de estudio de la musicología 8 .

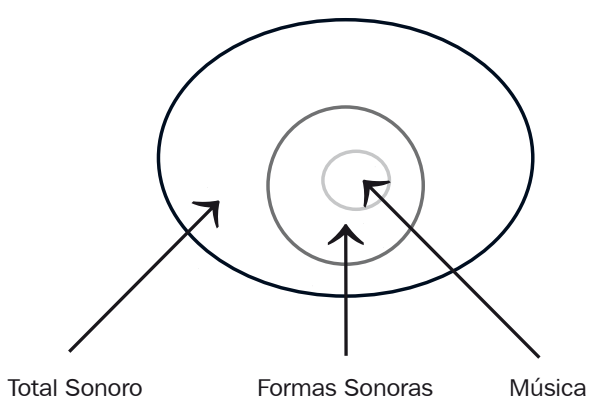

Figura $2 \sim$ Representación gráfica de la delimitación de los objetos de estudio.

Se trata aquí de ampliar la perspectiva de investigación semiológica a aquellos campos en los que el producto de la actividad poiética es una forma sonora, más allá de intervenir en o ser calificada como música. ¿Qué juicios de valor y de gusto, qué grupos de descripciones verbales producen determinadas formas sonoras según nos encontremos en la posición del fabricante, intérprete, compositor o hacedor de las mismas, o bien como analistas u oyentes?

\section{$1 \cdot$ EL TIMBRE DE LAS FORMAS SONORAS}

Organizadas o no, participando de una estructura cerrada o en estado de proceso, algunas formas sonoras, no solo la música, pueden suscitar juicios de valor y de gusto entre los oyentes ( $\mathrm{e}$ entre los que contamos a los propios compositores!): las expresiones «el sonido de Coltrane» o «el sonido del mar» o «el sonido del teclado Yamaha DX7» o «el sonido de George Martin» no refieren a ningún «texto»o «mensaje», sino a una imagen interior. Frecuentemente, para referirnos a esta experiencia «del sonido de» utilizamos la palabra «timbre». Así, las expresiones «el sonido del corno inglés»,

8 Notemos la paradoja que se produce en el momento de pensar todos los sonidos posibles: los convertimos inmediatamente en formas sonoras. 
«el sonido de George Harrison», el sonido de Detroit o «el sonido de los '80", reenvían a un cierto conjunto de rasgos pertinentes que permitirían su reconocimiento.

A este tipo de interpretantes los podríamos reunir en la categoría juicios de atribución, que es como clásicamente se enmarca el problema del timbre. Sin embargo, los procesos semióticos que desencadena son mucho más numerosos y contradictorios. A continuación, intentaremos formar grupos y subgrupos de interpretantes de acuerdo a los paradigmas poiético, estésico y neutro, aunque estas categorías por momentos pierden sentido, ya que como veremos, muchas flotan entre estos polos y esa es su característica más fuerte.

Llegado a este punto, para hacer esto necesitaremos realizar una nueva reformulación de nuestra idea: el estudio de las formas sonoras no coincide con el estudio de lo audible. Lo audible es un universo infinitamente vasto y a la vez parcial: hay formas sonoras que existen en la imaginación y por el contrario, los meros fenómenos audibles no marcados por alguna intención humana, carecen de entidad simbólica.

\subsection{Poiética de las formas sonoras}

Me encanta poder hablar de lo sagrado que tiene el sonido.

De esa arcilla con la que, si se tiene la visión del cielo, se puede elaborar el cielo. $\sim$ Luis Alberto Spinetta

\footnotetext{
Heidegger no evoca ningún dicho ni ningún decir del amigo, ni aunque fuera amistoso. La voz de este amigo no habla necesariamente. Este amigo podría ser afásico. Incluso se podría ser fisicamente sordo sin dejar de portarlo bei sich, cerca de sí, a través de su voz. Jacques Derrida, en El oído de Heidegger
}

En su libro dedicado a Berlioz Máscara y fantasma (1970), Michel Guiomar plantea, inspirado en el filósofo Gastón Bachelard, una fenomenología de la imaginación sonora que permitiría indagar y establecer cierta historia de 
las imágenes sonoras, sus transformaciones y sobre todo su anclaje en el inconsciente del compositor. El autor, citando a Jean Claude Piguet, sostiene que «El compositor piensa pues la música de la imagen antes que la imagen musical y piensa la imagen musical antes que los sonidos» (Guiomar, 1970: 98). Para el compositor François Bayle, que se apoya tanto en la semiótica de Peirce como en la fenomenología de la imaginación de G.Bachelard, declara que «es justamente el privilegio del mundo de las imágenes poder ofrecer grados de libertad infinitos, jamás contradichos por los límites de la realidad» (Pires, 2007).

La poiética de las formas sonoras está guiada y organizada alrededor de imágenes mentales y representaciones intencionales de sus productores, quienes dejan huellas de su trabajo en la materia sonora en una multiplicidad de niveles. Por eso, sostenemos que la concepción de nivel neutro de Nattiez no es equivocada ni errónea, sino que está limitada solo al nivel del texto, mientras que la totalidad de las poiéticas implicadas en la producción de las formas sonoras implica una multiplicidad de niveles inmanentes simultáneos que interactúan entre sí. Dada la naturaleza misma de la escritura musical y la continua «diferancia» entre visible y audible, entre audible y representable, entre representable y comunicable, que el timbre es relacionado a menudo con lo inefable. Consideramos que esta inefabilidad se asienta en el aspecto energético, cuasi viviente de las formas sonoras.

\section{$1.2 \cdot$ Poiética externa}

Hemos dividido las definiciones dadas por compositores e investigadores en «El timbre, metáfora para la composición» (Barrière, 199I) analizándolas a partir del juicio de atribución que realiza cada uno de los autores en relación al timbre. De esta manera encontramos que algunos autores consideran:

a) el timbre consecuencia de una causa instrumental

b) el timbre como consecuencia de las cualidades o virtudes del músico

c) el timbre consecuencia de las relaciones de organización

d) el timbre como consecuencia de la interacción parametral

e) aquellos que lo consideran relacionado a información sensible proveniente de otros sentidos (tacto, visión) 
a) Claude Cadoz: «en el origen, el nexo del timbre a la causa productora del fenómeno sonoro es una evidencia tan natural que no da lugar a dudas. La palabra designaba, en el principio, un instrumento, una especie de tambor con bordonas que le daban al sonido un color característico» (Cadoz, I991: 19).

b) Tokumaru: «los instrumentistas de kotudumu, como de otros instrumentos, quieren desarrollar su originalidad en el timbre, si lo logran, los auditores reconocen a los músicos por un solo ataque» (Tokumaru, I991: 93).

c) James Dillon: «el timbre como «forma», como Gestalt, posee una «estabilidad de red», que constituye por esencia un fenómeno musical y no un fenómeno puramente psicológico [...] así, él es la resultante polimorfa de relaciones de organización» (Dillon, I991: 288).

d) Dalbavie: "[...] le timbre est constitué par les autres paramètres musicaux comme le rhytme, la hauteur, l'intensité, et contient en lui un potentiel synthetique qui en fait un element "a part" (Dalvabie, I991: 303). Piencikowsky lo define como "dimensión acústica susceptible de formalización» (Piencikowsky, 1991: 82).

e) Saariaho: «la noción que designo con el término genérico de timbre es ya una síntesis de varios componentes. Entre éstos mencionaré en particular el brillo (que incluye la relación puro/ruido ) y la textura (granular/liso)»(Saariaho I99I: 4I2).

Entendemos que esta mínima lista nos permite comprender la casi imposibilidad de un acuerdo sobre el objeto mismo del cual se habla entre un grupo de especialistas reunidos por la más importante institución musical de la época (el IRCAM).

\subsection{El aspecto fantasmático del timbre}

Nos preguntamos si existe alguna relación entre la extrema movilidad de los procesos semióticos desencadenados por las formas sonoras y el carácter fantasmático que se le atribuye al timbre. Algunas definiciones dadas por compositores y teóricos que otorgan un mayor peso específico a la poiética parecen apoyar esta idea: 
Manoury: "como un caminante en el desierto, que ve alejarse el horizonte a medida que avanza, los compositores pierden toda posibilidad de definir el timbre a partir del momento en que buscan controlarlo» (Manoury, I991: 293).

Bonnet: «apenas nos permite acercarnos que inmediatamente se nos escapa, dejándonos en un abismo de perplejidad, como lo hiciera una nebulosa fugitiva, no dejando tras ella mas que una estela opaca, huella efímera de su realidad inaprensible» (Bonnet, 1991: 335).

Chion: «si un fenómeno [...] se ofrece solo a uno de mis sentidos, es un fantasma, y no se acercará a la existencia real sino es capaz de hablar a mis otros sentidos, como por ejemplo el viento que, cuando es violento, se hace visible en una alteración violenta del paisaje» (Chion, 1998: 53). También: «el sonido es, al mismo tiempo que objeto sonoro, sonido de una cosa, y esta cosa puede ser figurada como un cuerpo imaginario que habita en las tres dimensiones del espacio, que tiene un volumen [...] una masa, una densidad, una velocidad, sin ser forzosamente nombrable. [...] El sonido es la presencia fantasma de esta cosa» (Chion, I998: 57).

Guiomar: «ciertas imágenes no son solamente fantasmas sino haces de fantasmas. [...] si el fantasma sonoro deviene imagen, una imagen musical puede estar en el origen de una estructura y esta estructura en el origen de toda una obra» (Guiomar, I970: I02).

No deja de sorprendernos la sinonimia en la lengua española entre fantasma y espectro. ¿Es lo espectral aquello fantasmático del sonido? ¿Es el timbre aquello que produce «la inquietante extrañeza», tal es la traducción en francés del artículo de Sigmund Freud Das Unheimlich? ¿O este fenómeno solo ocurre cuando una importante cantidad de significaciones se condensa en una sola forma sonora? ¿Quién o qué es? ¿Dónde está? ¿Qué hace? ¿Hacia dónde se dirige? Preguntas que normalmente nos hacemos por razones de supervivencia cuando escuchamos sonidos en un lugar desconocido, pueden ser las preguntas que guíen nuestra investigación en el futuro.

Parecería que el reconocimiento de una persona -no necesariamente material, no necesariamente humana - en tanto productor imaginario de las formas sonoras es la condición que permite categorizar una forma sonora como música. Como lo afirma Cochrane, 
la mayor parte del debate filosófico sobre los poderes expresivos de la música conciernen a la persona. Los filósofos difieren sobre qué tipo de persona es, pero la afirmación básica es que cuando escuchamos emoción en música necesariamente imaginamos o tenemos la sensación de una persona a la cual esas emociones le pertenecen. (Cochrane, 2010: 264)

\section{$2 \cdot$ ESTÉSICA}

Complementariamente a este aspecto inasible que revela la poiética, del lado de la percepción aparece la misteriosa facultad de reconocimiento, que permite reconstruir con enorme precisión en ciertas condiciones y para algunos oyentes los gestos de producción y remontar a partir de las huellas espectrales a qué, quiénes, cómo y dónde fueron producidas permitiendo a ciertos oyentes en ciertas condiciones, reconstruir algunas de las acciones, condiciones acústicas e intenciones a partir de las cuales fueron creadas. La investigación de la etnomusicóloga Cornelia Fales, se detiene justamente en este punto . En The paradox of timbre se pregunta:

¿Cómo podemos conciliar el éxito con el que identificamos una fuente con el hecho de que el sonido que escuchamos es demostrablemente diferente en el timbre que el sonido emitido por la fuente en cuestión? La resolución de esta paradoja es compleja y esperamos que surja en el resto de este documento, pero por ahora, basta decir que el sistema auditivo sí identifica las fuentes, pero identifica una versión de las fuentes que puede no coincidir siempre con la versión existente en el mundo físico. En cambio, percibe las fuentes de acuerdo con sus propias expectativas, fuentes que son consistentes con fuentes similares identificadas en el pasado, o que tienen características típicas de un entorno, aunque el análisis digital podría mostrar que son completamente anómalas según cualquier estándar mensurable. La paradoja existe porque aunque la versión percibida de una fuente sea diferente a la señal física que representa, es una versión que funciona en nuestro mundo, es una versión que es consistente con las versiones de otros oyentes, es una versión «real», «lo suficiente como para permitirnos lidiar con el entorno físico». La versión es esa fuente para nosotros, y mientras continúe funcionando, no necesitamos otra. Que la paradoja del timbre rara vez es apreciada por los oyentes comunes es una señal de 
que el sistema que procesa los sonidos para la percepción también cuida de mantener sus operaciones transformativas fuera de la conciencia de los oyentes. (Fales, 2002: 58)

La «huella espectral» es considerada por algunos teóricos como Robert Cogan como un equivalente a las huellas digitales de los seres humanos. En New Images of Musical Sound (1984), a partir de análisis espectrales de interpretaciones de obras de diversos estilos y procedencias culturales y comparaciones de diversas interpretaciones de una misma obra (por ejemplo, las versiones de Demus y Schnabel sobre el primer movimiento de la Sonata op.rog de L.v. Beethoven), el autor muestra cómo las formas sonoras llevan inscriptas las «huellas dactilares» de quien las ha producido (Cogan, 1984). Estas huellas, consecuencias de gestos de producción/construcción, funcionan como marcas identitarias en varios niveles para el campo estésico: permiten identificar objetos sonoros (el sonido del pizzicato), el sistema escalar (el sonido del pentafonismo), instrumentos y ejemplares de instrumentos (el sonido de un violín Stradivarius), intérpretes (el sonido de Ella Fitzgerald), como así también «el sonido» de compositores, productores discográficos, soportes, altoparlantes, espacios. En cuál, hemos llamado a estos gestos impresos en la materia sonora "gestos-huella» para diferenciarlos de las meras acciones no intencionales de los intérpretes durante la performance y de las acciones y gestos que no tienen consecuencias sobre el sonido pero sí sobre la audiencia. Convergentemente con las intenciones de producción impresas en la huella espectral, ciertos oyentes pueden intentar, tal como lo describe Nattiez, «reconstruir activa y dinámicamente el mensaje».

Para Mac Adams (citado por Cadoz) el proceso de reconstrucción de las intenciones de producción es "un procesamiento dirigido por conceptos» (Cadoz, I99i: 27) en el que los

los datos recibidos son indicios considerados como los efectos de una causa, que es el objetivo al que tiende la percepción. En el caso de los sonidos vocales, por ejemplo una inferencia del lugar de articulación en la cavidad bucal, permitiría al sistema perceptivo reconocer una misma consonante en diversos fonemas mientras que las condiciones de sonoridad consecutiva de la consonante difieren. (Cadoz, I991: 27) 
La cantidad de capas diferentes que constituyen una forma sonora compleja hace casi imposible separar en el espectro aquellas marcas que corresponden a cada uno de los procesos y objetos intervinientes en el resultado final. Imaginemos el simple sonido de una guitarra, marca $x$, ejemplar $y$, tocada por el músico $z$, grabada por el ingeniero de sonido $m$, con un micrófono $n$ en un sistema $o$, reproducido en un sistema a en el recinto $b$. Cada una de esas etapas constructivas y performáticas podrían compararse a capas geológicas, susceptibles de ser reconocidas/reconstruidas por grupos de oyentes con competencias diferentes. El especialista en acústica arquitectónica, el productor discográfico, el técnico de grabación, el intérprete, el fabricante de instrumentos, el compositor, el oyente «audiófilo», podrán reconocer marcas en diferentes niveles, impresas por el trabajo de cada uno de los intervinientes en la producción de una forma sonora, sean estos directos o indirectos. Por ejemplo, muchos especialistas en grabación son capaces de «recuperar» el tipo y posición de los micrófonos empleados en una toma. Un instrumentista será capaz de inferir a partir de la escucha las intenciones asociadas a un determinado "toque», un luthier será capaz de identificar y jerarquizar las cualidades de diferentes materiales con los que está habituado a trabajar. Gracias a las huellas que las formas sonoras dejan en la memoria es posible para los creadores imaginar virtualidades, comportamientos posibles de una fuente sonora, no sólo reconocerlas cuando se producen sonidos materialmente diferentes a los retenidos en la memoria, sino también proyectar comportamientos no oídos de esas fuentes.

\section{$3 \cdot$ Esbozo de UNA TIPOLOGÍA DE REENVÍos PROdUCIDOS}

A continuación intentaremos hacer una lista provisoria de los diferentes tipos de reenvíos que hemos podido tipificar.

a) Reenvíos a otras formas sonoras (semiosis introversiva)

b) Reenvíos a conceptos y sentimientos (semiosis extroversiva)

c) Reenvíos a eventos en el tiempo (funciones de alarma, rememoración, anuncio)

d) Reenvíos a su propia fuente material o imaginaria (reenvíos a causas a distintos niveles) 
e) Reenvíos sobre su propia materia y forma de desarrollo en el tiempo (autosemiosis)

f) Reenvíos a sensaciones recibidas por otros sentidos (color, tacto, olfato)

a) Reenvíos a otras formas sonoras o reenvíos introversivos: comprende a todos aquellos casos en los que los fenómenos de implicación/realización tienen lugar. Puede ocurrir en la música, pero también en la poesía, en las narraciones orales en las que más allá de sus aspectos semánticos, los rasgos paralingüísticos como la entonación, las pausas, las velocidades y cambios de velocidades en que un enunciado es modalizado, produciendo expectaciones de continuación.

b) Reenvíos a conceptos y sentimientos: en este caso las formas sonoras son interpretadas a partir del modelo lingüístico binario propuesto por Ferdinand de Saussure. Es el caso de los lenguajes que hablamos y comprendemos, pero también de agenciamientos de formas sonoras que tanto en el cine como en la comunicación masiva funcionan de manera híper estable produciendo reenvíos altamente previsibles en los que es posible hablar de un significante que reenvía a un significado, como los musemas estudiados por Tagg o las figuras tópicas estudiadas por Agawu.

c) Reenvíos a eventos presentes, pasados o futuros: eventos presentes (llamadas / convocatorias celebración / encuentro seducción / amor denuncia / protesta trabajo demarcación de territorios); eventos en el pasado (conmemoración exequias; representación de lo ausente / evocación); eventos futuros (guerra / arenga profecía / alarma anunciación).

d) Reenvíos a las fuentes materiales: es el caso más común, simplificado al extremo como escucha indicial por Chion. La posibilidad de hacer inferencias a partir de rastros acústicos no se limita a las causas materiales del sonido, sino que también es posible volver a las diferentes etapas de sus condiciones de producción, ya sean acciones intencionales para producir un sonido o no. El universo del índice es mucho más complejo que la referencia del sonido a su causa material, como lo demuestra el trabajo sobre Shofar del discípulo psicoanalista de Freud, Theodor Reik que citaremos a continuación. 
$\sim$ Reenvíos a las fuentes imaginarias: hay casos específicos en los que una forma sonora reenvía a una causa imaginaria o a una causa ausente. La idea de la evocación de una presencia «en ausencia» o presencia fantasmática recorre textos extremadamente diversos. En el extraordinario trabajo de Theordor Reik sobre El Shofar, el autor remonta desde el sonido y la descripción de las figuras melódicas tradicionales utilizadas en el ritual del pueblo judío a causas virtuales cada vez más abstractas e inmateriales, desde el quejido de la voz del carnero, al gemido del toro, a la voz del padre asesinado y finalmente a la voz de dios (Reik, 1995). Otro ejemplo interesante en el que los sonidos reenvían a fuentes sonoras imaginarias aparece en el trabajo que Annie Laboussière dedica al Solo de corno inglés del zer acto de Tristán e Isolda (1859) de Richard Wagner. En el mismo, la autora realiza un cuadro paradigmático en el cual se ponen «en serie» comentarios y análisis del célebre solo, desde el momento de su creación hasta el momento de publicación del artículo, en el que se incluyen las diversas interpretaciones sobre la fuente del sonido, del cual nadie duda que en su nivel material es un corno inglés, sin embargo los críticos asignan ese sonido a una interesante variedad de fuentes:

$\sim$ Cotard, I895: «se escucha de un pastor tocando en el chalumeau una melodía llena de tristeza».

$\sim$ Tiersot, I895: «el canto juega un rol directo en la acción [...] presagio funesto cuando Tristán cree ver a Isolda».

$\sim$ D'Annunzio, I90I: «el pastor modulaba sobre su delgado chalumeau la melodía imperecedera que le habían transmitido sus ancestros».

Fourcaud, I886: «un pastor suspira sobre su mussette una melodía popular».

Kobbe, 1969: «el pastor se pone a escrutar el océano tocando su flauta». A esta diversidad interpretativa, debemos sumar la perspectiva del propio compositor, que relaciona el solo con el canto de un gondoliero veneciano y con el análisis del propio Schneider quien lo relaciona con el ranz de vaches suizo. (Schneider, 2013:5)

e) Este último caso, que podría nombrarse autosemiosis no debería confundirse con los reenvíos introversivos descriptos por Nattiez. La autosemiosis sería aquella en la que un sonido reenvía a sí mismo, como ocurre en todos los fenómenos de escucha repetitiva, en la escu- 
cha reducida propuesta por Schaeffer, durante la construcción de instrumentos en la que el luthier debe constatar el resultado de su trabajo

y eventualmente modificarlo, en la síntesis de sonido y en todos los fenómenos en los que la creación sonora necesita de la estabilidad del evento vibratorio para penetrar en su naturaleza, es decir en momentos en que el sonido se convierte efectivamente en conciencia del espesor del presente y definitivamente no debe ser confundida con los reenvíos de una estructura musical a sus posibles continuaciones (fenómenos de implicación/realización según Narmour/Meyer). Los fenómenos de autosemiosis fueron claramente descriptos por Pierre Schaeffer en ocasión de referirse a la escucha reducida y al resultado de dicho acto que es el objeto musical, acción por la cual el sonido reenvía a sus cualidades y relaciones inmanentes.

\section{$4 \cdot$ El Nivel NeUtro de LAS Formas SONORAS}

El estudio de nivel neutro de las formas sonoras se recubre totalmente con las disciplinas científicas existentes que estudian el sonido, las vibraciones fonógenas, las formas y sistemas de su producción en sus diferentes niveles de materialidad, por lo cuál quedan totalmente fuera del alcance de este trabajo. Acústica, ingeniería de sonido, síntesis, análisis musical, musical data mining, psicoacústica, organología, ingeniería, modelos físicos, acústica de recintos, modelos espectrales son todas formas de análisis y modelización del nivel neutro. Intentaremos en el gráfico que aparece al final del trabajo representar parcialmente la complejidad de niveles materiales entealazado, cada uno susceptible de una perspectiva tripartita.

\section{$5 \cdot$ Conclusiones}

1. Las formas sonoras son la consecuencia del hacer intencional de un individuo o de un grupo o colectividad que, por mediación de un gesto de producción o escucha, imprime su huella en un soporte material (sea este un instrumento, un papel, una grabación) o inmaterial, como la memoria o la imaginación. Esta huella, consecuencia del gesto constructivo o expresivo podría pensarse como una signatura, una firma y sello de quién o quiénes, 
cómo y con qué fueron producidas. El concepto de formas sonoras simbólicas es operativo para diferenciarlo del concepto "sonido" que se opone generalmente al ruido y, a la vez, indica el conjunto total de sonidos y ruidos (un grupo no puede incluirse a si mismo como un sub grupo de sí mismo). 2. Diferenciarlo de la noción de objeto sonoro schaefferiana que se refiere solamente a las formas sonoras fijas en un soporte. Diferenciarlo de los sonidos y ruidos no animados por una intención o un gesto de producción o de escucha. Consideramos que el acto intencional de escuchar recorta formas sonoras, mas allá de la inexistencia eventual de una intención poiética «detrás» de la fuente sonora.

3. Tematizar y desbrozar la complejidad de la palabra «sonido» que alude simultáneamente y sin explicitarlo al fenómeno percibido, a la señal acústica y al fenómeno imaginado. Las formas sonoras están constituidas por un nivel material de existencia pero este aspecto no agota su naturaleza. Como todo fenómeno simbólico, las formas sonoras existen en la mente de sus productores y creadores mas allá y antes de su existencia material y luego, en forma distinta, al instanciarse en una señal física, dando lugar al fenómeno percibido.

4. Distinguir los niveles de pertinencia en el discurso sobre «el sonido»: por ejemplo cuando Chion escribe sobre el sonido (y no sobre un cierto sonido concreto) hace referencia a una cierta actitud de escucha típica del estilo acusmático que transforma el sonido del vuelo de una mosca o el sonido de una gota de agua en una forma sonora que luego de ser grabada y recortada del contexto causal podrá ser eventualmente experimentada gracias a la escucha reducida en tanto objeto sonoro. Cuando Stockhausen escribe sobre «el sonido», el objeto al que apunta no es el mismo. Por ejemplo en "How time passes», Stockhausen se refiere a un modelo vibratorio ideal, trascendental y cosmológico que se proyecta en todos los niveles musicales: forma, ritmo, altura, espectro, cuya propiedad fundamental son las proporciones de tiempo implicadas en las relaciones entre períodos encabalgados unos dentro de otros, apreciables en un espectro teórico, no concreto.

El estudio semiológico de las formas sonoras debería mostrar, poner en serie y tematizar la apasionante pluralidad de discursos posibles sobre el sonido, más allá de su existencia material irreversible, en tanto objeto de reflexión teórica que se sustrae al paso del tiempo. En todo caso, no hay «sonido» en tanto un campo definido e indubitable sobre el cual se apoya- 
ría la percepción sino una multiplicidad infinita de formas sonoras, implicando cada una, una poiética específica.

El objeto «sonido» del intérprete, del acusmático, del acústico, del urbanista o del productor discográfico, sólo es el mismo a condición de ser reducido a una descripción de nivel neutro que solo tenga en cuenta sus propiedades físicas. Por eso, la noción de forma sonoro-simbólica fuerza a pensar en su carácter específico.

Si para los Pitagóricos la estructura de los sonidos armónicos reenvía al orden cosmológico, para Rameau a la «Naturaleza», para Schenker a la santa trinidad, para Stockhausen a una estructura inherente al tiempo ocurriendo a múltiples velocidades simultáneas, resulta evidente que cada uno de estos autores no se está refiriendo a un sonido concreto, percibido y existente físicamente, al sonido de alguna cosa, sino a una imagen interior que se encuentra fuera de las erosiones y accidentes de la temporalidad. ¿Es útil usar la misma palabra para hablar de este fenómeno imaginario que para el fenómeno acústico, el fenómeno imaginado y el fenómeno percibido? $\mathrm{O}$ bien, ¿es que la naturaleza del sonido reposa en esta ambigüedad? El proceso de ampliación reformulación del universo de las formas sonoras va a ser decisivo para la desterritorialización del concepto de música, desde el siglo xx hasta la actualidad, que lleva a la aparición de artes limítrofes como la acusmática, el diseño sonoro, el arte audio, la creación radiofónica, que explican la importancia de tomar en cuenta un cuadro mucho más grande para comprender las producciones artísticas de los últimos cincuenta años. La redefinición de la noción de escucha en tanto categoría de la teoría musical, las tecnologías de toma de sonido, grabación, procesamiento, producción y difusión han expandido de tal manera el universo de formas sonoras posibles que una semiología de este campo se torna imprescindible. En el siguiente cuadro representamos algunas de las disciplinas que estudian las formas sonoras, agrupadas a partir de los paradigmas poiético, estésico y neutro.

Como es posible visualizar (figura 3), la multiplicidad de puntos de vista y los diferentes niveles en los que el mismo puede ser construido o creado, evidencia la complejidad de la definición del timbre. 


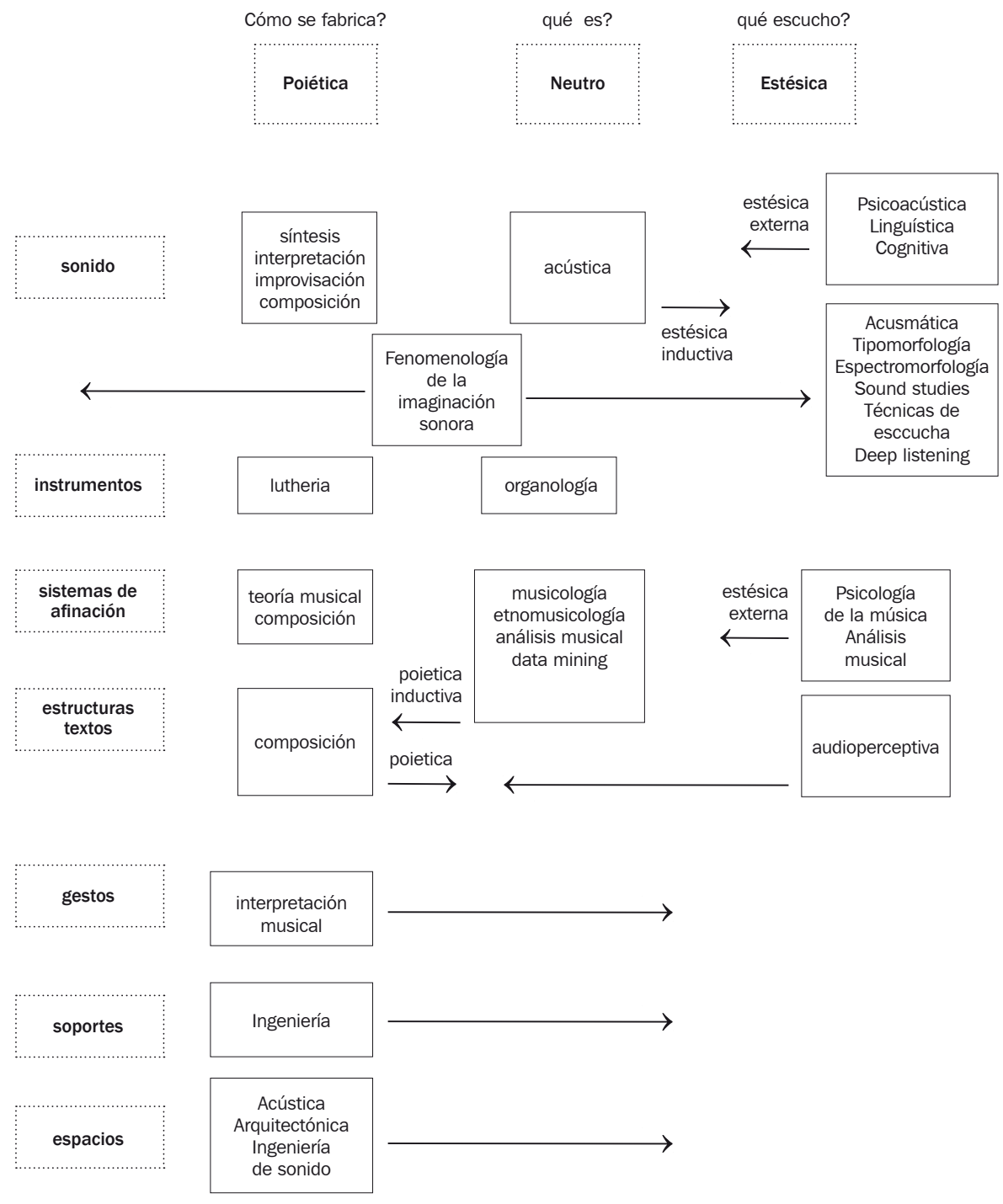

Figura $3 \sim$ Algunas de las disciplinas que estudian las formas sonoras, agrupadas a partir de los paradigmas poiético, estésico y neutro. 


\section{Bibliografía}

BATES, E. (2012). What studios do? Journal on the Art of Record Production, no. 7 BONNET, A. (1991). La part de l'insaisissable. en J-B Barrière (Ed.), Le timbre, métaphore pour la composition, pp. 335 - 351. Paris: Christian Bourgois Editeur

CADOz, c. (1991). Timbre et causalité. En J-B Barrière (Ed.), Le timbre, métaphore pour la com- position, pp. 17 - 46. Paris: IRCAM, Christian Bourgois Editeur CAUSSE, R. (1991). Sourdine et "timbre" des instruments à vent. En Jean-Baptiste Barrière (Ed.) Le timbre, métaphore pour la composition, pp. 217 - 224. Paris: IRCAM, Christian Bourgois Editeur

ChEYronnaud, J. (2012). Un endroit tranquille. À propos de "bruit", marqueur de reproche. Communications, vol. 90, no. 1, pp. 197 - 214

Chion, M. (1998). Du son a la chose. Analyse Musicale, no. 11, pp. 53 - 58 (1996). La dissolution de la notion du timbre. Analyse Musicale, no. 3, pp. $7-8$

FALES, C. (2002). The paradox of timbre. Ethnomusicology, Vol. 46, No. 1 (Winter), pp. $56-95$

Guiomar, M. (1970). Le Masque Et Le Fantasme: L'imagination de la Matière Sonore Dans la Pensée Musicale de Berlioz. Paris: Éditions José Corti GRELA, D. (2007). La consideración analítica del espacio en las formas sonoras. Revista del Instituto Superior de Música, no. 11

KINTZLER, C. (2003). La musique comme fiction et comme monde. Revue DEMéter, recuperado de: http://demeter.revue.univ- lille3.fr/manieres/kintzler. pdf

LABUSSIÈre, A. (1992). Die alte Weise. Une analyse sémiologique du solo de cor anglais du 3me acte de Tristan et Isolde. Analyse musicale, no. 27, pp 30 - 53

LAssus, M. P. (2010). Bachelard Musicien. Une philosophie des silences et des timbres. Lille : Presses Universitaires du Septentrion

MANOURY, P. (1991). Les limites de la notion de timbre. En J.B. Barrière (Ed.), Le timbre, mé- taphore pour la composition, pp. 293 - 302. Paris: IRCAM, Christian Bourgois Editeur

molino, J. (1975). Fait musical et sémiologie de la musique. Musique en Jeu, no. 17 , pp. $37-62$

- (2009). La musique et le geste. En J. Molino, Le singe musicien: Essais de sémiologie et d'anthropologie de la musique. Paris: Éditions Actes Sud

NATTIEZ, J.J. (1993). Comunicación en clase. Curso "Les grandes courants de I'analyse musicale au XXème siècle» Faculté de Musique. Université de Montréal - (1987). Musicologie Générale et Sémiologie. Paris: Christian Bourgois Editeur 
(2007). Le timbre est-il un paramètre secondaire? Les Cahiers de la

Société québecoise de recherche en musique, vol. 9, no 1- 2, pp. 13 - 24

(1993). Le combat de Chronos et d'Orphée. Paris: Christian Bourgois

Editeur

(2004). Ethnomusicologie et significations musicales. L'homme: Revue

Française d'Anthropologie. vol. 171-172, pp. 53 - 81. Recuperado de: https:// Ihomme.revues.org/24859

- (1998). Fidelidad, autenticidad y juicio crítico. CodeXXI, Revista de la Comunicación Musical, pp. 15 - 45

PIRES , I. (2007). Entretien avec François Bayle. Revue DEMéter, diciembre 2007.

Recuperado de: http://www.univ-lille3.fr/revues/demeter/entretiens/bayle.pdf

REIK, T. (1995). El ritual: estudio psicoanalítico de los ritos religiosos. Buenos

Aires: Acme Agalma Editorial

SAD, J. L. (2011). Texto Musical, acusmática, timbre. VOXES, vol. 2, pp. 24 - 55

SCHAEFfer, P. (1966). Traité des Objets Musicaux. Paris: Seuil

SCHAEFFNER, A. (1968). Origine des instruments de musique: introduction

ethnologique à l'historie de la musique instrumentale. Paris: Mouton Éditeur

SCHNEIDER, M. (2013). Vers une approche comparative de la structure et de la signification du solo de cor anglais dans le troisième acte de Tristan. Analyse musicale, no. 70, pp. 7 - 14

SMALLEY, D. (1997). Spectromorphology: explaining sound-shapes. Organised

Sound, vol.2, no.2, pp. 107 - 126

TAGG, P. (2015). The Urgent Reform of Music Theory. Contribution to Festschrift for Jean-Jacques Nattiez. Recuperado de: https://www.tagg.org/html/JJN7Oyrs.htm

TOKUMARU, y. (1991). Le timbre dans la musique japonaise. En J.B. Barrière (Ed.), Le timbre, métaphore pour la composition, pp. 90 - 97. Paris: IRCAM, Christian Bourgois Editeur

\section{Registro bibliográfico}

JoRGe SAD Levi: «Pensar en formas sonoro-simbólicas.

Desarrollo de un concepto para el estudio semiológico del timbre", en Revista del Instituto Superior de Música, número 17, Instituto Superior de Música, Santa Fe, UNL, República Argentina, 2020, pp. 60-85.

\section{Descriptores / Describers}

Música $\cdot$ timbre $\cdot$ formas sonoras 